\title{
Del ensayo y sus alrededores
}

Federico Patán

Universidad Nacional Autónoma de México

Pudiéramos afirmar lo siguiente: mientras no se me pidan certezas sobre algún tema, creo saber de él lo suficiente para defenderme. Sin embargo, cuando tal petición surge y me enfrento a la necesidad de explicarme en torno de un campo de estudio, también aparecen las inseguridades, puestas al descubierto por las muchas lagunas de información que de pronto hallo en mí. Como la solicitud de datos viene del exterior, me veo en la necesidad de no mostrar vulnerabilidades, que son fáciles de esconder a la mirada propia cuando del tema hablamos interiormente. Así, el ensayo fue de pronto una obligación surgida por necesidades de trabajo, y a examinarlo dediqué mi tiempo. Y descubrí, claro está, huecos obligatorios de llenar. Como si el ensayo fuera un animal elusivo y yo un cazador que a su captura estuviera, en tránsito por los campos de la crítica y, acaso mejor, por las complicadas selvas de la teoría literaria.

El ensayo nos es familiar, acaso sin habernos dado mucha cuenta de ello. Aparece de pronto en las páginas de nuestro periódico acostumbrado, si bien prefiere como hábitat las revistas, sean de divulgación o académicas. En ocasiones varios de tales ensayos se reúnen en grupo y dan pie a un libro cuya erudición varía de acuerdo con las virtudes del autor. Cuando somos maestros, el ensayo se transforma para nuestros alumnos en una temida herramienta de medición. Noto, y no he ahondado todavía en la cuestión, que el ensayo de periódico, el de revista, el acogido en volumen, el de mis alumnos y varios otros aún no localizados guardan aires de familia pese a mostrar, asimismo, diferencias.

Tengo pues, como inicio de este deambular por el tema, un nombre: el de ensayo. Me permito entonces la pregunta obvia: ¿qué es exactamente un ensayo? Pregunta sencilla que no necesariamente desemboca en una respuesta igual de sencilla. Son los problemas que vienen si la curiosidad nos lleva a hurgar más allá de la superficie. Por tanto, lo aconsejable es buscar las raíces. Digamos, el nombre dado a esta creatura. Las primeras investigaciones 
no fueron arduas y trajeron algunos datos preliminares. La palabra tiene su origen en un tiempo muy distante de nosotros y en el griego clásico, donde exagion significaba "el acto de pesar algo", el procedimiento mediante el cual se le daba peso a casi cualquier objeto. ¿Arriesgaré mucho si afirmo captar una especie de coincidencia entre la palabra antigua y la moderna? No lo creo. Después de todo, pudiera verse la escritura de un ensayo como el proceso mediante el cual se da peso a casi cualquier objeto cultural que despierte nuestro afán informativo. El diccionario español me asegura que "ensayo" viene del latín exagium, cuyo significado es el de "peso". Al parecer, vamos por el mismo camino hacia una misma línea de llegada. El diccionario inglés consultado, el Webster's, es un tanto más minucioso al exponer el desarrollo del término. También arranca con la palabra latina, dándole como traducción la de "ensayo de peso", palabra que llega al francés como "essai" y luego al inglés medio como "assay". ¿Y en francés qué ocurre? Que "essai" significa el intento hecho por conseguir algo, que poco a poco se va convirtiendo en el sentido que suele tener esta palabra en lo general y, desde luego, cuando se transforma en término literario. El crítico español Pedro Aullón de Haro, en un libro bastante complejo llamado Teoria del ensayo, confirma mis sospechas: incluso en alemán la palabra significa "un intento". ${ }^{1}$ No tengo escape: un ensayo, e incluso un ensayo literario, es el intento de conseguir algo e "intento" se me transforma en la idea con la que he de trabajar.

Pero entonces llego a un deslinde: aquel donde separo "ensayo" como idea general de "ensayo" como entidad literaria. ¿Qué rasgos individuales definen a este último? Seguiré con los diccionarios, cuya obligación es la de ser muy concisos y severos en cuanto a definiciones se refiere. El Diccionario de la lengua española, de la Real Academia, no pierde el tiempo y afirma: "Escrito generalmente breve, sin el aparato ni la extensión que requiere un tratado completo". Si no he leído mal, al "ensayo" se le caracteriza en función de lo que parecen deficiencias, ya que en los campos de la literatura habita otro animal, de nombre "tratado", cuyo acercamiento a un tema es de mayor riqueza. He de confesar que no me parece un inicio muy prometedor para una actividad literaria. Si permitimos al Webster's una segunda oportunidad de intervenir, lo escucharemos afirmar que ensayo es "a short literary composition dealing with a single subject, usually from a personal point of view and without attempting completeness". Una vez más tropiezo con lo que parece una deficiencia: en un ensayo no se procura la cabalidad de exa-

' Pedro Aullón De Haro, Teoria del ensayo, p. 45. 
men, si bien asimismo encuentro un rasgo nuevo: suele estar presente un punto de vista personal, elemento cuya importancia irá creciendo a lo largo de estas páginas.

Arriesgo entonces una opinión: sin duda esa calidad de incompleto es una virtud. Sin duda dar un punto de vista personal acerca de algo es, por naturaleza, un enfoque parcial y, en razón de tal parcialidad, un acercamiento honesto. Porque nos estaremos limitando a expresar "esto es lo que pienso de" y en este punto se agrega cualquier tema de los muchos que abundan en nuestro rededor o en nuestro interior, alli donde viven las preocupaciones que nos desasosiegan. Paso entonces a otra afirmación obvia: al parecer no hay limites a las posibilidades de un ensayo, excepto aquellas que pertenecen a quien lo haya escrito. Allí está la belleza real del género: no conoce más límite que la inteligencia del autor. En razón de esto, Cuddon afirma que el ensayo "is one of the most flexible and adaptable of all literary forms", 2 para agregar enseguida que el ensayo presenta "a personal and reflective informality". ${ }^{3}$ Una vez más, una palabra que de entrada se entendería como queja termina por revelar una virtud: la informalidad. Porque las palabras significan cosas diferentes en contextos diferentes y, aquí, "informalidad" no tiene el sentido de algo dejado en la superficie del agua, sino de algo que se zambulle con movimientos gráciles. La gracia es importante cuando se definen los movimientos de ese ente peculiar llamado "ensayo".

Pero no quiero olvidar la definición expresada por el crítico mexicano José Luis Martínez. Para él, "la expresión más concisa y exacta que corre a propósito del ensayo es "literatura de ideas"”. ${ }^{4}$ Ideas, agrego, que han sido moldeadas por la personalidad del escritor. Por tanto, me parece, va conformándose la imagen de que el ensayo es el intento que hace un autor por expresar sus opiniones acerca de un tema determinado. No se trata, deduzco, de trabajar con datos incuestionables, al modo de los científicos, buscando con ello establecer una verdad inconmovible acerca de algo. Deducción que de inmediato me refutarán muchos científicos con datos asimismo incuestionables. El ensayo literario, tengo para mí, ofrece un diálogo, una explicación meramente posible acerca de un tema, incluso simplemente las dudas que nos estropean la tranquilidad mental. Un ensayo pudiera ser el esfuerzo que hacemos para entender las cosas. De ser así, nunca nombre tan lleno de significado como aquel de "ensayo".

2 J. A. Cuddon, Dictionary of Literary Terms and Literary Theory, p. 307.

${ }^{3}$ Idem.

“ José Luis Martinez, "Introducción" a El ensayo mexicano moderno, t. I, p. 9. 
Hablando de ideas, acaso la anterior explique otro hecho. ¿Quién escribe ensayos? Quiero decir, quién los escribe por razones íntimas y no por especificaciones académicas, periodísticas o laborales. Lo aborda todo tipo de personas interesadas en los aspectos culturales del mundo, tomándose aquí cultural en su sentido más generoso. Intentemos algo: descubrir en nuestra época un autor de narrativa, de poesía o de drama totalmente ajeno a la escritura de ensayos. Como la literatura alberga personas de lo más estrafalarias, es muy probable que terminemos por encontrar dos o tres ejemplos de lo pedido, mas difícilmente un número mayor. Entonces, solicita nuestro asombro el que casi todo escritor sienta la necesidad, e incluso la urgencia, de probarse en la composición de ensayos. ¿Acaso narrativa, poesía o drama no son suficientes? Pues no, no lo son; al menos no para satisfacer ciertas necesidades de expresión. Incluso es de mencionar a Thomas Mann (18751955) y su idea de una novela impregnada de ensayo, una especie de acuerdo entre los dos géneros. Según nos informa Claudio Magris, las novelas tipo ensayo son de lo más común en la literatura austriaca moderna, y lo confirma mencionando a Herman Bröch y Robert Musil, entre varios más.

El ensayo parece haber vivido entre nosotros desde los tiempos menos historiables. Martínez arriesga la siguiente opinión: el ensayo es "tan antiguo que pueden reconocerse esbozos ensayísticos en libros orientales y del Antiguo Testamento y en varios textos griegos y latinos". ${ }^{5}$ Es de recordar a sir Francis Bacon (1561-1626). En su carta de 1612 a Enrique, príncipe de Gales, mediante la cual le dedica sus ensayos, dice: "that hath made me choose to write certain brief notes, set down rather significantly than curiously, which I have called Essays. The word is late, but the thing is ancient. For Seneca's epistles to Lucilius, if one mark them well, are but essays..."6 Ningún riesgo en proponer las Meditaciones de Marco Aurelio, posibles de clasificar como memorias, autobiografia, filosofía y, desde luego, ensayo.

El concepto de ensayo moderno tiene un padre. Francés, según lo ha determinado la historia. Porque Michel de Montaigne (1533-1592) acuñó la palabra en $1580 \mathrm{y}$, acaso, fue el primero en examinar la naturaleza de ese modo de escritura que él llevó a una de sus perfecciones. Algunas de sus ideas quedaron expresadas ya a lo largo de mi ensayo sobre el ensayo, pero una de ellas adquiere importancia dado mi propósito. Dijo Montaigne: "no estoy obligado a ser perfecto ni a concentrarme en una sola materia; varío cuando bien me place, entregándome a la duda y a la incertidumbre, y

\footnotetext{
s Ibid., p. 7.

"Francis BACON, Selected Writings, p. 6.
} 
a mi manera habitual, que es la ignorancia".? Aparte de la coquetería implicita en llamar ignorancia a su modo habitual, dos palabras son de subrayar en esto: duda e incertumbre. Como si volviéramos a una idea ya expresada, aquella de aprovechar el ensayo para alcanzar una iluminación 0 , al menos, para dejar precisadas nuestras inquietudes. El crítico inglés $\mathrm{A}$. K. Thorlby comentó lo anterior de esta manera: "The title Essais was a modest one. [Montaigne] appears to have conceived an essay as an assay, a trial of an idea, of himself, of his judgment, of his experience". 8 Una vez más se habla del ensayo en función de aspectos que parecerían disminuir su estatura y que, sin embargo, la fortalecen. Veo en esta condición del ensayo una enseñanza muy valiosa: el aprovechamiento de nuestras debilidades para mejorar nuestra cultura. Montaigne hablaba de que era ignorante en lo concerniente a muchas cosas. Pero el simple reconocimiento de tal ignorancia es un primer paso muy sólido en el camino a superarla. Si se conoce al enemigo es posible concebir una estrategia para derrotarlo o, en el peor de los casos, oponerle resistencia. El escribir ensayos es, ¿por qué no?, parte de tal estrategia.

No faltan ideas para el intento de definir la naturaleza del ensayo. Por ejemplo, José Ortega y Gasset dijo en cierta ocasión que el ensayo "es la ciencia menos la prueba explícita". ${ }^{9}$ Regresa a nosotros un viejo amigo, al que saludamos páginas atrás. Según esto, no escribimos ensayos para ofrecer datos sólidos acerca de un tema, sino para meditar en torno de él, para darle penetración a nuestras dudas, para proponer una explicación aceptable respecto a algo, para abrirnos al diálogo con otros. Es tarea de los lectores, sin duda, aceptar, discutir o rechazar cualquiera de nuestras ideas, sobre todo cuando están expresadas sin la prueba explícita. Son las reglas del juego. En El hombre sin cualidades, el novelista austriaco Robert Musil afirmó lo siguiente acerca de ese modo tan personal de medir el mundo que llamamos ensayo: "It is the unique and unalterable form that a man's inner life assumes in a decisive thought". ${ }^{10}$ Una de las palabras aquí importantes es "interior" y la otra "decisivo". Hay una relación muy clara entre la idea de un modo personal de examinar el mundo y esa vida interior. Porque si el hombre se construye como ser humano del exterior hacia el interior, luego transformará el exterior desde el interior y, claro, es la idea expresada por

${ }^{7}$ P. Aullón de Haro, op. cit., 9.

${ }^{8}$ A. K. ThORLBY, "Michel de Montaigne", en The Penguin Companion to Literature: European, p. 544.

9 P. Aullón de HaRo, op. cit., 10.

${ }^{10}$ Robert Musı, The Man Without Qualities, t. I, p. 301. 
Musil. "Decisivo" es un elemento nuevo. Si Montaigne hablaba de dudas, Musil escribe sobre firmeza en la expresión de nuestros pensamientos. Finalmente, nada nos impide ser categóricos en la expresión de nuestras dudas.

Pasemos a George Lukács (1885-1971), quien se asomó al ensayo desde un punto de vista diferente. De acuerdo con él: "El ensayo es un juicio, pero lo esencial en él, lo que decide su valor, no es la sentencia (como en el sistema), sino el proceso mismo de juzgar". " Interesante propuesta. Al leer un ensayo lo que seguimos ante todo es el encadenamiento de ideas ofrecido por un cierto escritor, y nuestra preocupación central es la ruta que ese autor ha seguido. Por así decirlo, un ensayo significa el modo en que la mente de una persona nos revela el proceso de su actividad; esta revelación gradual es la enseñanza obtenida de leer el ensayo, viniendo a ser la conclusión el momento culminante del viaje. Aprendemos algo, bastante, mucho mientras avanzamos a lo largo de un ensayo, incluso si el autor es, finalmente, una figura menor o incluso de mente no muy despierta.

Miguel de Unamuno (1864-1936), él mismo un escritor de ensayos muy inteligente, un ideador de pensamientos de lo más sutil, dijo que "el ensayo es un tejido de aforismo y definiciones". ${ }^{2}$ Es la idea de Lukács vista desde otra perspectiva, pues el filósofo español propone que seguir la unión de aforismos a lo largo de un texto es la actividad importante en la lectura de un ensayo. Y el propio Aullón, de ninguna manera un escritor fácil debido a cierto barroquismo de su estilo, en uno de sus momentos de mayor claridad dijo que "escribe ensayísticamente quien compone experimentando, quien de este modo da vueltas de aquí para allá, cuestiona, manosea, prueba, reflexiona..." ${ }^{\prime 3}$ Lo cual es otra manera de expresar lo mismo: cuando se escribe un ensayo se "intenta" llegar a alguna conclusión, e "intentar" nos regresa al inicio de este, desde luego, ensayo. Ahora, el crítico italiano Claudio Magris: "El ensayo es, por definición, un género oblicuo, que habla de una cosa para hablar también -y con frecuencia, principalmente- de otra, cuyo tema nunca se reduce a su objeto explícito". ${ }^{14}$ Lo cual aproxima estas consideraciones a una idea de Jorge Luis Borges: un cuento cuenta algo para hablar de algo más. Hete aquí un parentesco inesperado.

Dicho todo lo anterior, abordemos otra cuestión: ¿cuáles temas son los adecuados para un ensayo? Todo lo existente bajo el sol, desde la flor más

" P. Aullón de Haro, op. cit., p. 129.

${ }^{12}$ Idem.

13 Ibid., p. 45.

${ }^{14}$ Claudio MAGris, El mito habsburgico en la literatura austriaca moderna, p. 22. 
humilde hasta la idea más abstracta. Porque si el ensayo es un modo de observar el mundo, todo lo de ese mundo le pertenece. Francis Bacon ino escribió "Of Parents and Children", "Of Travel", "Of Delays", que no parecen cuestiones demasiado sesudas y que sin embargo, en sus manos, seso adquirieron? De Quincey examinó la posibilidad de que el asesinato fuera un arte. Robert Louis Stevenson no desdeñó temas como el de "Talk and Talkers", el de "An Apology for Idlers" y la curiosa propuesta "On the Enjoyment of Unpleasant Places". Oscar Wilde recuperó el diálogo como vestido del ensayo, haciendo esto en aquel titulado "The Critic as Artist". O bien E. M. Forster haciendo un retrato de Virginia Woolf o Virginia Woolf observando morir a una polilla.

¿Recuerdan ese ensayo, "La muerte de la polilla"? Nada demasiado importante: la autora nos describe los esfuerzos de una polilla por cruzar el cristal de una ventana. Desde luego, tarea imposible de realizar $\mathrm{y}$, más al punto, una derrota incomprensible para el insecto. El que finalmente muere sin entender qué mano invisible le impide llegar a su objetivo. Se diría que Virginia Woolf comprueba con muchos años de anticipación lo establecido por Magris. Porque la anécdota narrada es muy sencilla, pero trabaja en profundidad algunos aspectos de la existencia importantes. $Y$ tal es justamente nuestra creencia principal al describir un ensayo: para la mente despierta no hay tema pequeño; todo tema se encuentra alejado de una mente sin recursos. Y, desde luego, nada tan difícil como aprovechar lo sencillo para examinar lo complejo.

Así, un escritor aborda el ensayo para expresar alguna opinión personal acerca de algún tema en lo particular, a menudo sacando ventaja de temas menores para lidiar con asuntos importantes. Para José Luis Martínez el ensayo moderno es "un producto típico de la mentalidad indivualista que crea el Renacimiento...", 15 lo cual explica el acercamiento personal a un tema, que parece constituirse en una de las esencias del ensayo contemporáneo. Mucho del cual, si breve, consigue un hábitat lógico en periódicos y revistas. Cuando el autor tiene o conquista alguna importancia en el mundo literario, sus ensayos descubren la manera de transformarse en libros, donde sin duda hay una oportunidad más sólida de sobrevivir. Hace algunas semanas un libro llamado Por qué leer los clásicos me vino a las manos en una librería. Lo escribió Italo Calvino, un autor italiano cuyas obras gozo mucho. Es una de las razones por las que el libro saltó a mis manos. Otra, el tema: ¿por qué, en verdad, leer a los clásicos? Necesito apoyos muy convin- 
centes que transmitir a mis alumnos. Una tercera razón, que los clásicos de Calvino no incluyen, al menos en el volumen comentado, a William Shakespeare, excepto de un modo indirecto en el capítulo dedicado a Gerolamo Cardano; sin embargo, sí hay espacio para nombres que me son desconocidos: el propio Gerolamo Cardano, Gianmaria Ortes o Frances Ponge. Qué oportunidad maravillosa de acrecentar la interminable lista de autores por leer. Pero antes de hacerlo escuchando las pruebas de su bondad que Calvino pudiera aportar. Listo me encontraba, pues, a participar en un diálogo.

Pero acaso la razón principal que me llevó a comprar el libro fue algo un tanto más dificil de transformar en explicación seria: Italo Calvino tiene un agudo y delicioso sentido del buen humor, un modo de jugar con la literatura que, al menos en mi opinión y en este ensayo, lo sitúa junto a Rabelais, Sterne, Joyce, Borges y Cortázar. Lo cual significa un modo singular de mirar el mundo, modo de mirar que era mi interés medir. Buscaba, pues, la mente singular de Calvino. Antes de llegar a constituirse en libro los ensayos fueron material de periódicos y revistas. No son de gran extensión y no recuerdo ninguno mayor de diez páginas. Repitamos algo: el autor escribe de "sus" clásicos y no de los clásicos que todo mundo espera e incluso exige. Así que, como ensayo, el material satisface las características hasta el momento enumeradas. Incluyendo, no faltaba más, un acercamiento personal al tema, que no pocas veces se diría ofrecido como estímulo a la discusión. Al escribir sobre Jean-Jacques Rousseau, Calvino dice: "Todo lo que Jean-Jacques Rousseau piensa y hace me interesa mucho, pero todo me inspira un deseo incoercible de contradecirlo, de criticarlo, de discutir con él". ${ }^{6}$ Estamos quizá ante una de las razones más extrañas para leer a un autor: estar en desacuerdo con él y sin embargo gozarlo. Pero he aquí una lección muy positiva: nunca debemos temer a las ideas; sí debemos temer nuestra incapacidad de dialogar con ellas. Porque ese diálogo es nuestra vía a derrotarlas y nunca la será el darles la espalda por temor.

Hemos llegado al propósito central de escribir un ensayo. Pero no determinemos aún los valores de este medio de expresión, pues un terco problema de límites nos mira de frente. Sucede que el ensayo vive en compañía de una familia bastante populosa, y no va con las buenas costumbres el definir a un cierto personaje con el nombre de otro. A veces el ensayo y algún otro texto son parientes cercanos e incluso muy cercanos, pero hasta una diferencia mínima es una diferencia necesaria de anotar. Empiezo con el cuidadoso acercamiento de José Luis Martínez al problema. El "artículo" es un 
buen punto de partida. Para Martínez significa un modo de escritura relacionado con el periodismo, con interés mayor en los asuntos del día o de un cierto periodo de días; según el Webster's, nos encontramos ante "a factual piece of writing on a specific topic", donde "atenida a los hechos" es la diferencia notable respecto al ensayo. Porque (siempre desde la perspectiva de las definiciones y no de las prácticas) el prurito de un artículo es la objetividad. Lo sabemos, claro, la manera en que se busca ser objetivo es ya una expresión sutil de la subjetividad. De cualquier manera, "artículo" es nuestra aproximación mayor a esa imposibilidad periodística: el mero enunciado de hechos. ¿Otra diferencia? Que el "artículo" es de naturaleza muy perecedera. Rara vez se le embalsama en una antología, si bien ocasionalmente se le cita en materiales menos mortales por su constitución. Acaso su valor radique más en que es un hecho histórico (no importa cuán menor) y no una muestra de escritura excelsa.

Segunda etapa, el "estudio crítico". Martínez lo describe como una investigación escrita con cierto distanciamiento, sin interrupciones de lo sentimental, que además presenta mucho aparato erudito. Un pariente bastante lejanos del ensayo si por éste significamos un enfoque personal. Ahora bien, es del todo posible impregnar un estudio crítico con un punto de vista personal, pero entonces se presenta la siguiente cuestión: ¿a qué grado ser erudito en un ensayo? Si escribimos acerca de Mark Twain con la intención de presentarlo al lector desde un punto de vista crítico, ¿dónde poner la frontera entre "estudio crítico" y "ensayo"? ¿En que parámetros exactos se dejan atrás las severas tierras del estudio crítico y se avanza por los territorios del ensayo? He aquí un misterio. Pero si se dice "severas" acaso hallamos dado con una solución. En el "estudio crítico" se enumeran las fuentes de consulta, se hace cita de material ajeno, se intenta convencer al lector mediante las ideas personales y el manejo personal de las ideas ajenas, en ocasiones transformadas en paráfrasis y ocasionalmente asentadas tal como son. En el ensayo gozo la libertad de afirmar "esto es lo que pienso", con un subrayado definitivo del modo personal. Nada es necesario de probar científicamente, ya que nos limitamos a informar de lo que pensamos.

Me veo en peligro. ¿En serio no es indispensable probar algo? Mucha exigencia parece desde cualquier punto de vista. ¿Para qué escribir si no vamos a probar algo?, pudiera objetárseme. Veamos la cuestión con algo más de detalle. Si en un "ensayo crítico" insisto en que Mark Twain pertenece a la literatura misisipiana (¿estaré inventando una provincia amplia y nueva en la narrativa de Estados Unidos?), es mi obligación inevitable introducir cuanto material de apoyo me sea posible, para darle credibilidad a mis afirmaciones. Pero si escribo que, para mi en lo personal, tras mis lectu- 
ras muy personales, Twain es un escritor de la zona del Misisipi porque varias de sus obras más importantes se interesan en tal río y tal río es una especie de tutor espiritual del novelista, mi deber de ensayista es mostrarme lógico y claro en el desarrollo de esa tesis personal. Lo confieso, sin embargo, la línea divisoria entre ensayo y estudio crítico se mueve sin cesar, aumentando las dificultades de dar una descripción muy afinada y científica de ambas modalidades de escritura. Pero sin más he de aceptar otro punto: así ocurre con toda literatura. Será cuestión de ir modificando las etiquetas en obediencia a los caminos que abra la creación literaria.

¿Y un "tratado"? Uno de mis viejos consejeros, el Webster's, habla de "a systematic exposition in writing of a subject" y Martínez de un "estudio completo, arquitecturado y riguroso que pretende entregar toda la sabiduría existente sobre un tema..."17 Subrayo dos de las palabras: sistemático y completo. Si regreso a Mark Twain, sistemático pudiera significar la necesidad de examinar todos los autores posibles que hayan escrito sobre el Misisipi, para comparar sus enfoques del río, el simbolismo que acaso le atribuyan e, incluso, decidir en qué periodo hemos tenido más libros sobre ese tema y las causas de tal abundancia. Si en un tiempo esos escritos fueron literatura de frontera, bien pudieran ser hoy muestras de turismo narrativo. Y Mark Twain todo el tiempo como el elemento de comparación. Y la derivación de algunas conclusiones realmente académicas. Acaso unas quinientas páginas de concentrada erudición. Y la busca larga y tediosa de un editor valiente. $Y$ las reseñas.

¿Serán éstas una variedad de ensayo? No en su vestido común, como artículos de periódico o de revista. Breves y al punto, son un método sencillo para vengarnos de un escritor, si bien se les debiera limitar a la tarea de expresar una opinión honesta acerca de un libro. Es el puente que une al texto con los lectores y, por tanto, una importante actividad crítica. En ocasiones la reseña acrecienta sus límites, modifica sus propósitos y hace del examen de un libro reciente excusa para hablar del tema abordado en el libro o acerca del autor. Mas cuando se cambia el propósito de un texto se cambia su naturaleza.

Si pedimos a nuestros estudiantes que definan "tesis", responderán: pues un cierto número de páginas que debo escribir para obtener mi grado. Pero la palabra misma nos lleva por otros sitios: el trabajo de este tipo consiste en poner ante un jurado una "proposición que se mantiene con un razonamiento". Una buena tesis significa un alumno razonador; significa, además,

17 J. L. MARTínez, "Introducción" a El ensayo mexicano moderno, t. I, p. 12. 
que los maestros han cumplido un buen trabajo. Tan bueno que los estudiantes se van apartando de nosotros porque los hemos enseñado a contemplar el mundo con criterios personales. Criterios que se asientan por escrito $y$, de no ser excesiva la petición, en una prosa legible. No digo elegante, barroca, adornada, enriquecida sino tan solo legible, capaz de transmitir pensamientos. Por lo mismo, una "tesis" se acerca más al "estudio crítico" que al ensayo propiamente dicho.

Lo cual me lleva al término inglés "paper", definidor de una cierta actividad generalmente ocurrida hacia el final de los cursos. Final de curso que en español significa la entrega de un "ensayo". "Paper" y "ensayo". ¿Querremos describir lo mismo con estas palabras? ¿Ocurrirá que el término "paper" suavice la tarea de los estudiantes, al sonar menos demandante que el otro? Por tanto, ¿será ensayo una tarea de mayor envergadura? El resultado suele ser el mismo: por lo general un abordaje ingenuo de la literatura $y$ en casos excepcionales un modo agudo de comentarla. No me abandona la idea de que "paper" mengua las dificultades de los alumnos.

El buen ensayo ofrece mucho en breve espacio. Resulta ideal para iniciarse en algún tema, para acrecentar nuestro conocimiento del mismo. El ensayo es una vía cómoda (aunque no siempre fácil) de mantenernos al tanto de los desarrollos ocurridos en nuestro campo de especialización. Es, claro, un camino para expresar nuestras ideas sobre cualquier materia. Me arriesgo a la cursilería: un ensayo escrito desde el fondo del corazón y con el auxilio del cerebro es uno de los mejores modos de expresar: asi es como entiendo el mundo o algunos de sus aspectos.

\section{Bibliografía}

AULLÓN DE HARO, Pedro, Teoria del ensayo. Madrid, Verbum, 1992.

BACON, Francis, Selected Writings. Nueva York, The Modern Library, 1953.

Calvino, Italo, Por qué leer los clasicos. Trad. de Aurora Bernárdez. Barcelona, Tusquets, 1997. (Col. Fábula)

Cuddon, J. A., Dictionary of Literary Terms and Literary Theory. Harmondsworth, Penguin Books, 1992. 
MAGRIS, Claudio, El mito habsbürgico en la literatura austriaca moderna. Trad. de Guillermo FERNÁNDEZ. México, UNAM, Coordinación de Humanidades, 1998. (Serie Poemas y ensayos)

MARTINEZ, José Luis, "Introducción" a El ensayo mexicano moderno, t. I. México, FCE, 1971, pp. 7-27. (Serie Letras mexicanas)

MusIL, Robert, The Man Without Qualities, t. I. Trad. de Eithne WILKINS y Ernst KAISER. Londres, Picador Books, 1979.

Thorlby, A. K., "Michel de Montaigne", en The Penguin Companion to Literature: European. Harmonsworth, Penguin Books, 1969. 